\title{
Effect of Goat Milk Yogurt for Prevention Hypercholesterolamic in Animal Model Rat (Rattus norvegius) Based on the Expression of Inducible Nitric Oxide Synthase (INOS) and a description of Liver Histopathology
}

\author{
Chanif Mahdi ${ }^{1}$, Sukarno Hariyanto ${ }^{2}$, Masdiana C. Padaga ${ }^{2}$ \\ ${ }^{1}$ Chemistry Departement, Faculty of Mathematics and Natural Sciences, Universitas Brawijaya, Malang, Indonesia \\ ${ }^{2}$ Veterinary Medicine Program, University of Brawijaya, Malang, Indonesia
}

\begin{abstract}
The pattern of high consumption of fat can lead to hypercholesterolemia were accompanied by increased levels of LDL which resulted in LDL oxidation, accompanied by an inflammatory reaction that can lead to liver tissue damage resulting in increased expression of inducible Nitric Oxide Synthase (INOS) and changes in liver histopathology. The purpose of this study was to investigate the influence of goat milk yogurt supplementation on the expression of INOS and liver histopathology picture. This study used 20 male rats, Wistar strain aged 10-12 weeks, weighing 150-200g. Giving goat milk yogurt for 42 days with a dose of $300 \mathrm{mg} / \mathrm{kg}, 600 \mathrm{mg} / \mathrm{kg}$, and $900 \mathrm{mg} / \mathrm{kg}$ and giving dietary hypercholesterolemia by administering poached quail egg yolk, lard, and cholic acid by the stomach sonde for 14 days. Parameters measured were the expression of INOS and liver histopathology picture. The analysis used in this study is the One Way Analysis Of Variance (ANOVA) followed by Tukey test $5 \%$. The results showed that administration of goat milk yogurt as a precaution hypercholesterolemia at a dose of $300 \mathrm{mg} / \mathrm{kg}, 600 \mathrm{mg} / \mathrm{kg}$ and $900 \mathrm{mg} / \mathrm{kg}$ give a highly significant effect $(p<0.0 \mathrm{I})$ on the expression of INOS $(p<0.0 \mathrm{I})$. The overall Result of each treatment were $0.47 \pm 0.03 ; 6.72 \pm 0.11 ; 2.40 \pm 0.16 ; 1.11 \pm 0.07$ and $0.66 \pm 0.19$. Prevention with a dose of $900 \mathrm{mg} / \mathrm{kg}$ body weight is the most effective dose inhibits the expression of INOS. Prevention with a dose of $900 \mathrm{mg} / \mathrm{kg}$ showed that the histopathological picture of approaching normal circumstances. The conclusion of the study is the provision of goat milk yogurt as a preventive action with a dose of $900 \mathrm{mg} / \mathrm{kg}$ of the most effective to inhibit the expression of INOS and maintain normal liver histology in rats given diets hypercholesterolemia.
\end{abstract}

Keywords: Hypercholesterolemia, Expression of Inducible Nitric Oxide Synthase (INOS), goat's milk yogurt, liver histopathology

\section{INTRODUCTION}

Hypercholesterolemia is an increase in cholesterol levels exceed the normal limits. Normal cholesterol levels in humans 120 to 240 $\mathrm{mg} / \mathrm{dl}$, pet animals such as a dog of 150 to 300 $\mathrm{mg} / \mathrm{dl}$, and white mice 40-130 mg/dL (Murray, et al., 2003; Bauer, 2004). Conditions such as hypercholesterolemia in animal pet dogs and cats due to an unbalanced diet. This condition occurs about $25 \%$ to $44 \%$ in dogs in western countries (Guyton and Hall, 1997). Hypercholesterolemia common in dogs aged four years or more due to old age dog has decreased metabolism. High levels of blood cholesterol in hypercholesterolemic patients are one of the major risk factors for coronary heart disease (CHD) and atherosclerosis (Price, et al, 2006).

\footnotetext{
*Corresponding author e-mail: chanifmahdi@gmail.com
} 
Nitric oxide (NO) is a biological molecule that is found throughout the body, is produced by a number of cell types associated with the disease process would be detrimental and beneficial effects at the cellular level and vascular (Lorenz, et al., 2002). NO production catalyzed by the enzyme nitric oxide synthase (NOS) that is inducible nitric oxide synthase (INOS) (Young, et al., 2001). INOS expressed through the process of transcription and protein translation. INOS expression caused by the presence of free radicals, which activates Nuclear Factor Kappa Beta.

Liver function neutralizes toxins in the body. Liver eliminates toxins, metabolic wastes that are not useful to the body (Kardong, 2002). Liver tissue has a sinusoidal consisting of endothelial cells, pits cells, Kupffer cells and stellate Hepatic Cells (HSC). Kupffer cells and HSC cells play an important role in the process of liver fibrogenesis.

Yogurt is a drink with a relatively viscous texture and sour flavor that comes from raw milk that has been fermented. Yogurt is made through a fermentation process using a mixture of Lactobacillus bulgaricus, Lactobacillus acidophilus and Streptococcus thermophillus that can break down milk sugar (lactose) into lactic acid. The presence of lactic acid that causes sour yogurt. Specific aroma of yogurt consists of components carbonyl with diacetyl and acetaldehyde dominant (Ah-Leung, et al., 2006).

Goat's milk yogurt contains Lactic Acid Bacteria (LAB). Some types of LAB have a cell wall composed of lipoprotein that is able to bind cholesterol in the small intestine before the cholesterol absorbed by the body (Tamime and Robinson, 2007). BSH enzyme (Bile Salt hydrolase) will give a special advantage to the strains of lactic acid bacteria that grow in the competitive environment in the digestive tract by providing better resistance to bile salts, as well as help in lowering blood cholesterol levels (Roncada, et al., 2002). The cholesterol-lowering mechanism by BAL activity caused by enzymes that conjugate BSH bile salts, which are separated from glycine or taurine steroids, resulting in bile salt-free or conjugated (Kartini, 2002).

\section{MATERIALS AND METHODS}

\section{Preparation Animals Treatment}

In this study, the animals used were 20 rats (Rattus norvegicus) Wistar strain male age 10-12 weeks with a weight of 150-200 grams were obtained from the University of Gajah Mada UPHP. Rats were divided into 5 groups: negative control, positive control, prevention dose of 300 $\mathrm{mg} / \mathrm{kg}$, yogurt prevention dose of $600 \mathrm{mg} / \mathrm{kg}$ and $900 \mathrm{mg}$ dose yogurt prevention $/ \mathrm{kg}$.

\section{Goat Milk Yoghurt-Making}

Goat milk is poured into a $500 \mathrm{~mL}$ bottle $1000 \mathrm{~mL}$ Schott then covered with aluminum foil to avoid contamination. Schott pasteurized milk in bottles at a temperature of $72^{\circ} \mathrm{C}$ for 5 minutes and then cooled until the temperature drops to $43^{\circ} \mathrm{C}$. Inoculation mother culture with a concentration of $3 \%$ into $500 \mathrm{~mL}$ goat milk and homogenized slowly. Furthermore, incubated at $43^{\circ} \mathrm{C}$ for $4-8$ hours and up to an average $\mathrm{pH}$ of about 4.5-5 yogurt (Tamime and Robinson, 2007). After that, the goat's milk yogurt in freeze dry and stored at $4^{\circ} \mathrm{C}$.

\section{Dose Determination Goat Milk Yoghurt}

No dose calculation yogurt 3 i.e., to a dose of $300 \mathrm{mg} / \mathrm{kg}$, a dose of $600 \mathrm{mg} / \mathrm{kg}$ (Tamimme and Robinson, 2007) and a dose of $900 \mathrm{mg} / \mathrm{kg}$ body weight are as follows:

- $300=$ BW total of 4 mice in 1 box $/ 1000 \times 300$

- $600=$ BW total of 4 mice in 1 box/1000 x 600

- $900=\mathrm{BW}$ total of 4 mice in $1 \mathrm{box} / 1000 \times 900$

The dose of $300 \mathrm{mg} / \mathrm{kg}$ is used for group $\mathrm{C}$, a dose of $600 \mathrm{mg} / \mathrm{kg}$ for rat dose groups D and $900 \mathrm{mg} / \mathrm{kg}$ for rats group E. 


\section{Dietary Administration of Hyper- cholesterolemia In Mice}

Diet feeding method hypercholesterolemia (Gani, et al., 2013), making the feed hypercholesterolemia diet consisting of cholic acid $0.1 \%$, lard $10 \%$, and a poached quail egg yolk mixed $5 \%$ then the addition of water to a volume of $2 \mathrm{~mL}$. Hypercholesterolemia feeds given daily diet with sonde per rat. Giving cholesterol diet was conducted for 14 days.

\section{Analysis of Blood Cholesterol Levels}

The early stage of the analysis of blood cholesterol level is taking the blood through the veins coccygeal. Rat first placed in a tool restrain mice prior to blood sampling as much as $1 \mathrm{~mL}$. The collected blood was taken into microtube then centrifuged and serum was taken. Serum cholesterol levels were analyzed.

\section{Measurements INOS Expression In Liver Organ}

Immunohistochemical early stage is the stage deparaffination preparations namely, preparations soaked in a solution of xylol (2 times), absolute ethanol (2 times), alcohol 70\%, $30 \%$ alcohol and sterile distilled water each for 2 minutes. After that, stored for 24 hours at $4^{\circ} \mathrm{C}$ (Golgberg and Merkel, 2001). Further preparations drop with primary antibodies, antirat INOS. Then added a secondary antibody, antirabbit labeled with biotin in PBS (1: 200) for 1 hour at room temperature, then washed with PBS pH 7.4 ( $3 \times 5 \mathrm{~min})$. Furthermore, added the SAHRP in PBS (1: 500) for 40 minutes at room temperature, then washed with PBS pH $7.4(3 \times 5$ min). Then, chromogen DAB (3,3diaminobenzidine tetrahydrochloride) was added for 20 minutes at room temperature and then washed denganPBS $\mathrm{pH} \quad 7.4 \quad(3 \times 5 \quad \mathrm{~min})$. Furthermore, the counterstaining with hematoxylin Major dye sufficiently until the blue color looks washed with water and then rinsed $2 \times 5$ minutes and $1 \times 5$ minutes sterile distilled water and then left overnight at room temperature. After that, the mounting is done with entellan. The final result was observed under a light microscope with a magnification being (400x).

\section{Liver Mixture Analysis Method hematoxylin-eosin Staining}

Manufacture of histological preparations with HE staining. Staining of histological preparations according to Joseph (2009), liver tissue fixed in 10\% buffered formalin for 18-24 hours, included in distilled water for 1 hour then dehydrate with alcohol-rise 30\%, 50\%, 70\%, $80 \%, 90 \%$ to alcohol absolute. Network entered the solubility of alcohol xylol for 1 hour 2 times, liquid paraffin $2 \times 2$ hours for preparation and network disembedding into paraffin blocks. Cut the paraffin tissue blocks by microtome 4 microns thick, in cross section / cross then placed in glass objects. Incubated for disposal paraffin were then stained with HE staining. Observed under a microscope Olympus BX51. Observations were carried out by comparing the histology of control with each treatment.

\section{Data analysis}

Data obtained from the measurement results INOS expression in liver was analyzed using SPSS version 16.0 with test analysis of variance (ANOVA) and carried out the further analysis with Tukey test $(\alpha=5 \%)$ if there is a noticeable difference. Liver histopathological changes were analyzed qualitatively to see and compare the picture of liver histopathology of each group.

\section{RESULTS AND DISCUSSION}

Effect of Goat Milk Yogurt Against Syntheses Expression of Inducible Nitric Oxide (INOS) In Rat Liver Organ Marked hypercholesterolemia Diet Provision of hypercholesterolemia in rats diets may increase 
Nitric Oxide (NO) in liver tissue. Nitric Oxide NO catalyzed by the enzyme Inducible Nitric Oxide Syntheses (INOS). INOS expression measurement results on a variety of treatments showed significant differences.
Treatment INOS expression average $( \pm \mathrm{SD})$ Increased Expression of INOS (\%) Description: The difference notation $\mathrm{a}, \mathrm{b}, \mathrm{c}$ and $\mathrm{d}$ indicate a highly significant difference $(p<.01)$ between the treatment groups.

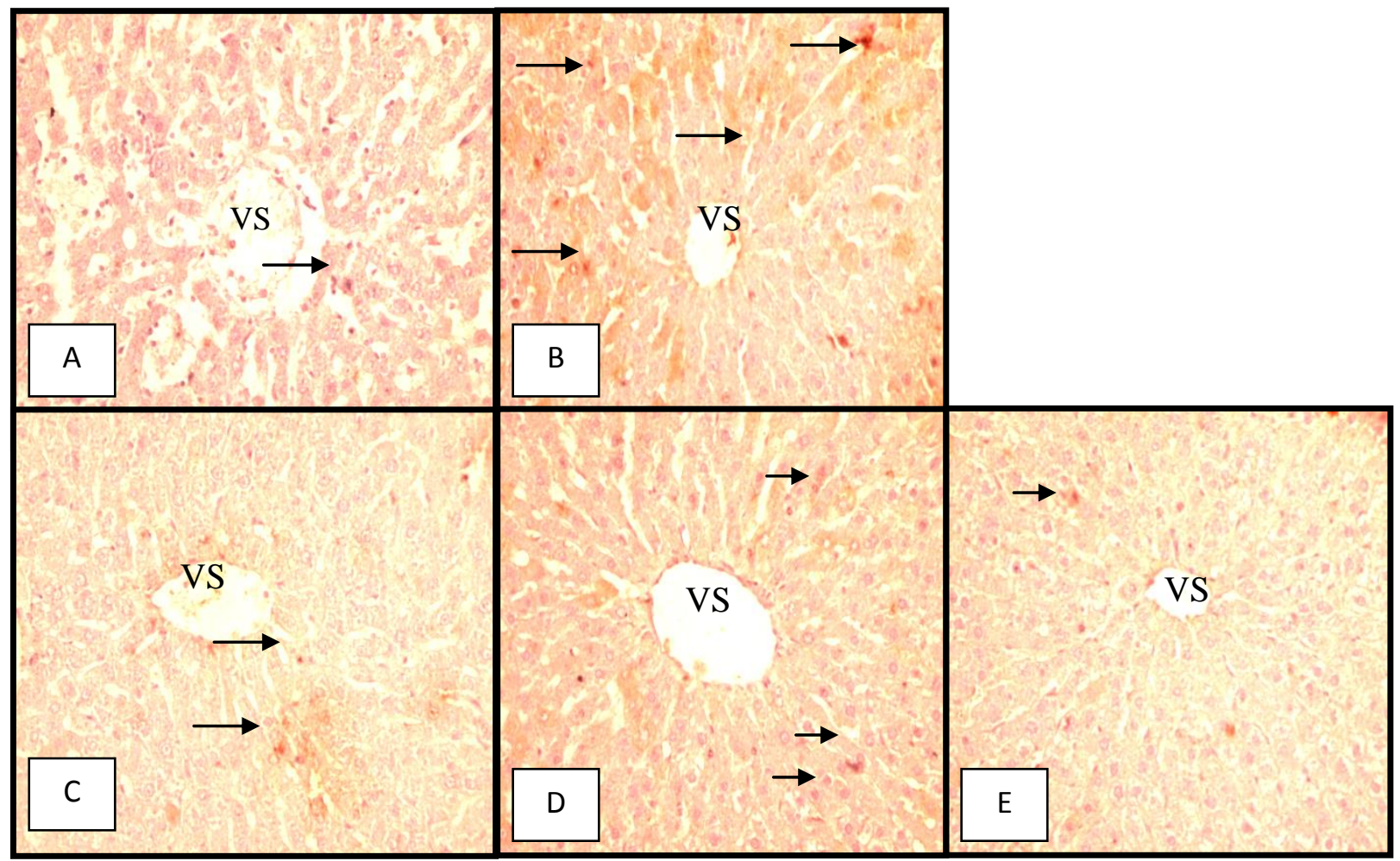

Figure I. Expression of Liver Organ INOS rat (400x magnification),: Expression INOS VS: the central vein.

Table I. Value liver INOS expression in a variety of treatment

\begin{tabular}{llr}
\hline \multicolumn{1}{c}{ Treatment } & \multicolumn{1}{c}{$\begin{array}{c}\text { Avarage INOS } \\
\text { expression (ISD) }\end{array}$} & INOS Expression (\%) \\
\hline Negative Control(A) & $0.47 \pm 0.03 \mathrm{a}$ & 7.00 \\
Positive Control (B) & $6.72 \pm 0.1 \mathrm{I}^{\mathrm{d}}$ & 100.00 \\
Dosis prevention 300mg/kg BW (C) & $2.40 \pm 0.16 \mathrm{c}$ & 35.71 \\
Dosis prevention 600mg/kg BW (D) & $1.01 \pm 0.07 \mathrm{~b}$ & 15.03 \\
Dosis prevention 900mg/kg BW (E) & $0.66 \pm 0.19 \mathrm{a}$ & 9.82 \\
\end{tabular}


Based on data in Table 1 show that the expression of INOS in group A is the smallest value when compared with other groups. This value is the value of INOS expression in groups of mice that have normal cholesterol levels. It is supported on the Fig. 1. Ann INOS expression that has at least when compared with other groups. 1 An INOS expression in the picture looks brown on the network. Brown color that is formed on the network due to the IHC analysis using DAB chromogen (3,3-diaminobenzidine tetrahydrochloride) that cause brown color when binds to avidin-biotin complex. The data in Table 1 also shows that the average value of the expression of INOS Group B is the highest value compared to group A, group $\mathrm{C}$, group $\mathrm{D}$ and group E. These results are consistent with studies conducted Fki, et al., (2005). That in groups of mice were fed a high cholesterol diet increased INOS expression in the liver compared to the normal group. Inducible Nitric Oxide Synthase (INOS) formed due to the activation of Nuclear Factor Kappa Beta $(\mathrm{NF} \kappa \beta)$ by free radicals. $\mathrm{NF} \kappa \beta$ activated translocate into the nucleus and binds to genes inflammation one gene INOS, then be transcribed into mRNA and translated into INOS INOS. The more nitric oxide (NO) produced, then also increase the expression of INOS in catalyzing the production of NO (Lukiati, 2012).

The effect of goat milk yogurt as a preventative measure hypercholesterolemia indicated by a decrease in the value of the expression of INOS group C, group D and group E compared to group B. In group C INOS expression was higher when compared to group $\mathrm{D}, \mathrm{E}$ and $\mathrm{A}$. This shows that the prevention of goat milk yogurt with a dose of $300 \mathrm{mg} / \mathrm{kg}$ and $600 \mathrm{mg} / \mathrm{kg}$ have not shown that the optimal dose for inhibiting the expression of INOS in rats fed a diet of hypercholesterolemia. INOS expression on prevention lowest dose shown in the dose of 900 $\mathrm{mg} / \mathrm{kg}$. INOS expression of group $\mathrm{E}$ showed there was no significant difference compared with INOS expression in normal mice. NO decrease in the group of rats caused prevention BAL activity that produces an enzyme that functions $\mathrm{BSH}$ deconjugated bile salts to produce bile salt-free. BSH enzyme will cause conjugated bile salts in the form of free cholic acid which is poorly absorbed by the small intestine so that bile salts return to the liver during enterohepatic circulation is reduced. Thus, the total cholesterol in the body to be reduced (Lukiati, 2012).

\section{Effect of Goat Milk Yogurt picture Histopathology Against Organ Animal Liver Model Rat (Rattus norvegicus) was given a diet hypercholesterolemia.}

Histopathological picture liver in this study shows that in the hypercholesterolemic state changes in the liver because the liver is the organ that plays an important role in the metabolism of cholesterol. Changes that occur can be observed in the form of fat found in liver tissue, infiltration of inflammatory cells such as monocytes and lymphocytes as well as changes in the form of necrosis of liver cells. Fatty liver caused by free radicals formed in the body due to the provision of hypercholesterolemia diet that accumulates in hepatocytes by forming micro and macro vacuole vacuoles in the cytoplasm of hepatocytes. This living tissue containing fat vacuoles. Preparations of liver with Hematoxylin-eosin staining (HE) in Figure 2 shows the comparison condition liver damage control group of mice (mice that have normal cholesterol levels), hypercholesterolemia mice, rats fed a diet of hypercholesterolemia at a dose of $300 \mathrm{mg}$ yoghurt prevention $/ \mathrm{kg}$, a dose of prevention yoghurt $600 \mathrm{mgkg} / \mathrm{body}$ weight and yoghurt prevention dose of $900 \mathrm{mg} / \mathrm{kg}$. 


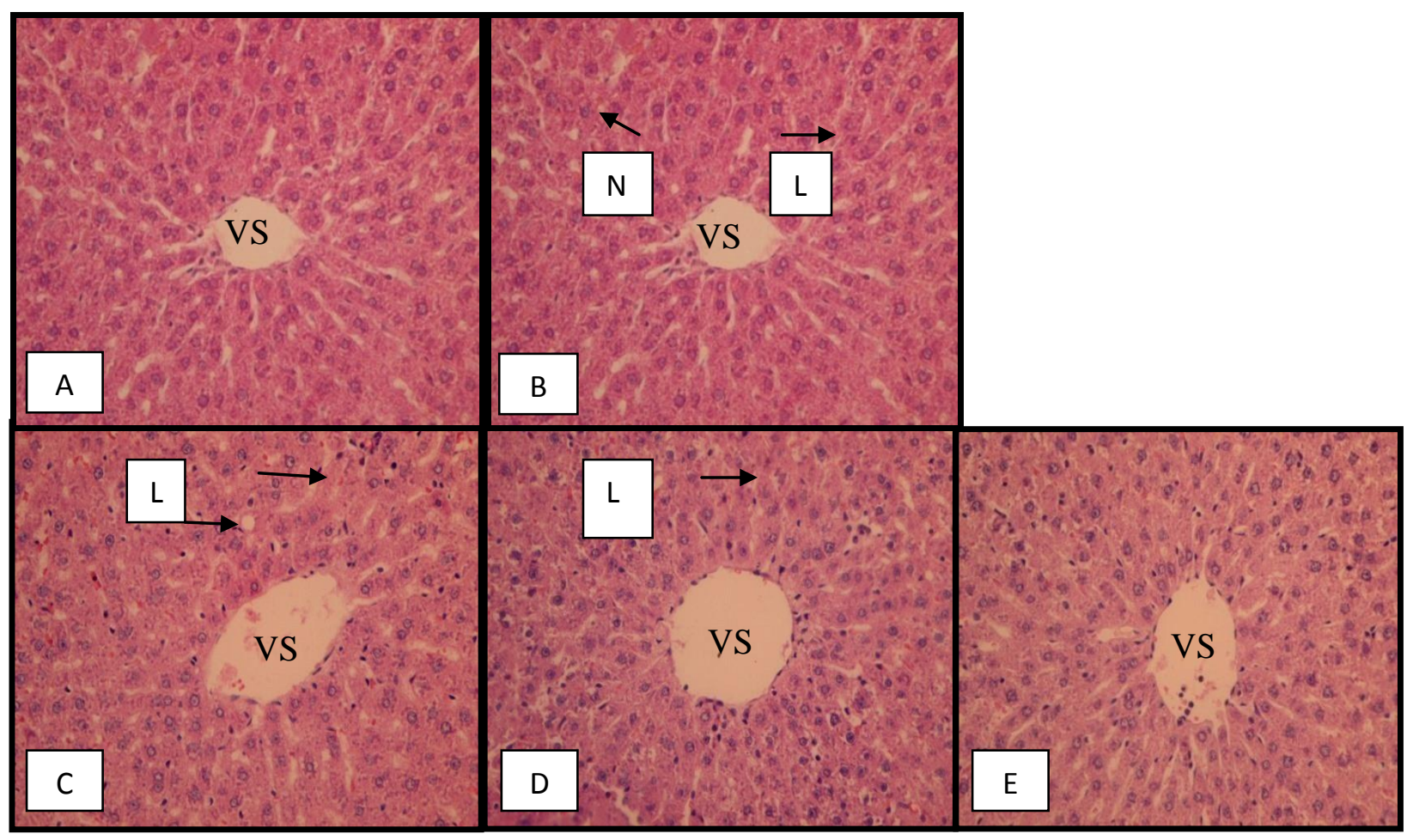

Figure 2. Histopathologic features Organ rat liver (HE, 400x), A. Negative Control (Normal), B. Positive Control (Hypercholesterolemia), C. Prevention dose of $300 \mathrm{mg} / \mathrm{kg}$, D. Prevention dose of $600 \mathrm{mg} / \mathrm{kg}$, a dose of E. Prevention $900 \mathrm{mg} / \mathrm{kg}$, approaching normal histology. L: Fatty; VS: Vena centralist; N: Necrosis.

Normal liver histology (Fig. 2A) indicate that the absence of inflammatory cells and not look for the fatty degeneration of the liver organ. This picture is consistent with research Wresdiyati, et al., (2006), where the normal picture in the liver of mice that have been stained with HE showed the liver does not seem the accumulation of fat, there are no inflammatory cells and liver cells stained basophilic, while the cytoplasm takes acidophilic color.

In the group of hypercholesterolemia (Fig. 2B) looks for fatty degeneration in almost all parts, the existence of some cells to die and there are many inflammatory cells. Fatty is due not hydrolyze triglycerides perfectly so that accumulates in the liver tissue. Previous research conducted by Oktaviana (2005), explains that the fatty degeneration leads to changes in cell structure that are the formation of vacuole- containing vacuoles in hepatocytes fat. At the time of coloring preparations, fat will disappear and the histopathological preparations look like empty space. This fatty degeneration occurs due to the conditions of hypercholesterolemia are free radicals excess in the body that causes the activity of the enzyme LPL be dropped, as it says Dugi (1997) that in hypercholesterolemic conditions will decrease the activity of LPL. This decrease in activity of LPL enzyme hydrolysis effect on the reduction in triglycerides (TG), the cell loses the power to issue TG $\mathrm{TG}$ resulting granules accumulate in the liver and fatty liver produces. Porth and Matfin (2008) says that the formation of free radicals in the liver causes cells to lose the power to issue TG causing fatty degeneration of the liver and cause liver cell function decline. Increased levels of free radicals further would 
lead to the death of liver cells in the form of necrosis (Ruswandi, 2005).

The high number of free radicals in hypercholesterolemic conditions also resulted in a decrease in the activity of antioxidant enzymes in the body, especially in the liver as SOD enzyme that functions as a catcher of free radicals (Balamurugan, et al., 2008). Decrease in SOD activity is a marker that is sensitive enough to indicate the presence of liver damage (Palanivel, et al., 2008). This causes an antioxidant enzyme is not able to neutralize the excess free radicals in the body, causing an imbalance between free radicals and antioxidants that cause oxidative stress. According to Valko, et al., (2006), oxidative stress can cause damage in the cell. Improvement of liver histopathology picture shown in the prevention group dose of $300 \mathrm{mg} / \mathrm{kg}$ (Fig. 2C), prevention group a dose of $600 \mathrm{mg} / \mathrm{kg}$ (Fig. 2D) and prevention group dose of 900 $\mathrm{mg} / \mathrm{kg}$ (Fig. 2E). On Fig. $2 \mathrm{C}$ seems that there is still a lot of fatty degeneration and many inflammatory cells and are still visible there dead cells. In the Fig. 2D namely the prevention dose of $600 \mathrm{mg} / \mathrm{kg}$ is still a lot of inflammatory cells but decreased fatty degeneration. In the Fig. $2 \mathrm{E}$ namely the prevention dose of $900 \mathrm{mg} / \mathrm{kg}$ liver histopathology picture getting closer to normal liver histopathology picture even though they appear to have little inflammatory cells and vacuoles that look like an empty space.

\section{CONCLUSION}

Giving goat's milk yogurt as preventive treatment at a dose of $900 \mathrm{mg} / \mathrm{kg}$ can inhibit the expression of INOS liver animal model rat (Rattus norvegicus) were given a diet hypercholesterolemia. Giving goat's milk yogurt as preventive treatment hypercholesterolemia at a dose of $900 \mathrm{mg} / \mathrm{kg}$ body weight to maintain normal liver histopathology picture of an animal model rat (Rattus norvegicus) were given a diet hypercholesterolemia.

\section{ACKNOWLEDGMENT}

We grateful and thank you very much to the head and staff Veterinary Laboratory/Public Health, Veterinary Medicine Program, University of Brawijaya, to the head and staff Laboratory of Pharmacognosy and Phytochemistry and the head and staff Laboratory of Biochemistry, University of Brawijaya for all support for this study.

\section{REFERENCES}

Ah-Leung, S., Bernard, H., Heresy, E., Paty, E., Rance, F. and Schelnmann, P., 2006, Allergy to Goat and Sheep Milk Cow's Milk Allergy Without, Allergy, 6I(II), I358-1365.

Ashari, K., Sutama, E., Juarini, P. and Arsana, 200I, Potential of Goat Milk and Development Problems, Yogyakarta: Gajah Mada University Press.

Fki, I., Bouaziz, M., Sahnoun, Z. and Sayadi, S., 2005, Hypocholesterolemic Effects of Phenolic-rich Extracts of Chemlali olive cultivar in Rats Fed a Cholesterol-rich Diet, Bioorg. Med. Chem., I3(18), 53625370.

Gani, N., 2013, Wistar Rat Plasma Lipid Profile which Hypercholesterolemia in Provision Gedi Red (Abelmoschus manihot L.)., Manado: Department of Chemistry Universitas Sam Ratulangi.

Guyton, A.C. and Hall, J.E., 1997, Textbook of Medical Physiology, In: Irawati Setiawan, translators, 1997, Translation of the Textbook of Medical Physiology, 9th Edition, Jakarta: EGC Publishers.

Hardiningsih, R. and Nurhidayat, N., 2006 The Effect of Consuming the Hypercholesterolemia Rationed Food to the Body Weight of White Rats Wistar with Administration of Lactic Acid Bacteria, Biodiversity, 7(2), I27-I30.

Harini, M. and Astirin O.P., 2009, Blood Cholesterol Level of Hypercholesterolemia Rat (Rattus 
norvegicus) After Treatment VCO, Bioscience Journal, I (2), 53-58.

Hseu, Y.C., Chang, W.H., Chen, C.S., Liao, J.W., Huang, C.J., Lu, F.J., et al., 2008, Antioxidant Activities of Toonasinensis Leaves Using Different Extracts Antioxidant Mode, Food Chem. Toxicol., 46(I), I05-II4.

Jung, C.H., Zhou S., Ding, G.X., Kim, J.H., Hong, M.H., Shin, Y.C., et al., 2006, Antihyperglycemic Activity of Herb Extracts on Streptozotocin-Induced Diabetic Rats, Biosci. Biotechnol. Biochemistry, 70(I0), 2556-2559.

Jusuf, A.A., 2009, Basic Histoteknik, Jakarta: Faculty of Medicine University of Indonesia.

Kardong, K.V., 2002, Vertebrates Company Anatomy, Function, Evolution, 3rd Edition, New York: Mc Graw Hill Companies Inc.

Kasim, E., Kurniawati, Y. and Nurhidayat, N., 2006, Utilization of Local Isolates Monascus purpureus for Lowering Blood Cholesterol in Rats Sprangue Dawley strain, Biodiversity, 7(2), I22-I24.

Lamenapa, M., 2005, Comparison of Lipid Profile and the development of atherosclerosis lesions in Wistar rats were given a diet with Diet Juice Juice of Pare Pare and Statins, Thesis, Universitas Diponogoro, Semarang.

Lorenz, S., Jordan, J. and Nava, E., 2002, The Nitric Oxide Pathway, J. Physiol. Biochem., 58(3), I79-I88.

Lukiati, B., Aulanni'am and Darmato, W., 20I2, Distribution Profile INOS and NO levels Rat Pancreas Diabetes mellitus Induction Results Post MLD-STZ administration temugiring Ethanol Extract (Curcuma heyneana), Journal of Veterinary Medicine, 6(2), 22-30.
Meyer, D.J. and Harvey, J.W., 2004, Veterinary Laboratory Medicine: Interpretation and Diagnosis, 3rd Edition, Philadelphia: Saunders. Link

Murray, R.K., Granner, D.K., Mayes, P.A. and Rodwell, V.W., 2003, Harper's Illustrated Biochemistry, 26th Edition, New York: McGraw-Hill.

Price, S.A. and Wilson, L.M., 2005, Pathophysiology: Clinical Concepts Of Desiase Process Vol.2, 6th Edition, Jakarta: EGC Publishers.

Ruswandi, D., 2005, Inhibition of Lipid Peroxidation by Fruit Extracts Crown God (Phaleria macrocarpa) on Rat Liver Function Disorders Due to Paracetamol, Thesis, Bogor Institute of Agriculture, Bogor.

Sirois, M., 2005, Laboratory Animal Medicine: Principles and Procedures, USA: Elsevier Inc.

Smith, J.B. and Mangkoewidjojo S., 1998, Maintenance, Breeding and Use of Experimental Animals in the Tropics, Jakarta: University Of Indonesia.

Tamime, A.Y. and Robinson R.K., 2007, Yoghurt Science and Technology, 3rd ed, Cambridge: Abington.

Tortora, G.J., 2005, Principles of Human Anatomy, I0th ed, USA: John Wiley \& Sons, Inc.

Tutik, W., Hartanta, A.B. and Astawan, M., 20II, Seaweed (Eucheuma Cottonii) Raise Level Superoxide dismutase (Sod) Rat Kidney Hypercholesterolemia, HAYATI J Biosci., I5(3), I05-I I0.

Wresdiyati, T. and Astawan, M., 2005, Detection by Immunohistochemical Antioxidant Superoxide Dismutase (SOD) on the Network Hypercholesterolemic Rats Fed Seaweed, Bogor: Faculty of Veterinary Medicine Bogor Institute of Agriculture. 